\title{
Bridging the gap between risk and recovery: a human needs approach
}

\author{
Ashimesh Roychowdhury ${ }^{1}$
}

The Psychiatrist (2011), 35, 68-73, doi: 10.1192/pb.bp.110.030759

${ }^{1}$ St Andrew's Healthcare, Northampton

Correspondence to

Ashimesh Roychowdhury

(aroychowdhury@standrew.co.uk)
Summary There is an inexorable drive in psychiatric services in the UK, including forensic services, towards organising and delivering care based on the principles of the recovery model. Hence recovery, and its subjective and objective measures, is the goal of these services and the standard by which the quality of the service is evaluated. At the same time, all psychiatric services are expected to practise evidence-based risk assessment and management practices and can be subject to severe criticism or sanctions if they do not do so. In this paper I set out the view that the values that underlie the recovery approach and the clinical risk assessment approach appear to be polar opposites. However, an understanding of human behaviour using a humanneeds model is an explanatory paradigm that underlies both the recovery model and the understanding of risk behaviour, and can thus unify these two approaches. Therefore a more explicit integration of this model into forensic care would be beneficial and there should be more research directed to the correlates of recoveryoriented measures and risk-related measures.

Declaration of interest None.
It is a moot point that psychiatric services in the UK, including forensic services, should have as its main (if not only) objective assisting the individual service user to 'recover' from mental disorder. ${ }^{1}$ The term 'assist' in recovery is used to align services with a commonly accepted definition of recovery, provided by Anthony who stated that 'recovery is a deeply personal, unique process of changing one's attitudes, values, feelings, goals, skills and roles. It is a way of living a satisfying, hopeful and contributing life, even with the limitations caused by illness. Recovery involves the development of new meaning and purpose in one's life as one grows beyond the catastrophic effects of mental illness'. ${ }^{2}$ Hence any attempt to measure recovery must include a personal narrative account as well as 'objective measures' such as paid employment, housing or number of close friendships. Several recent publications from all professional disciplines, such as From Values to Action: the CNOs Review of Mental Health Nursing from the Department of Health in $2006^{3}$ and the joint publication from the Royal College of Psychiatrists and the Social Care Institute for Excellence entitled A Common Purpose: Recovery in Future Mental Health Services in $2007^{4}$ have led the drive to ensure that services are organised and delivered at all levels based on recovery principles.

\section{What is recovery and what values drive it?}

Although it is open to debate whether recovery is a state or a process, Andresen et $a l^{5}$ set out the following components of the process of recovery:
- finding and maintaining hope, which includes having a sense of personal agency and optimism

- re-establishment of a positive identity, which includes identity with a positive sense of self that incorporates illness

- building a meaningful life, which includes making sense of the illness and finding a meaning in life despite the presence of illness

- taking responsibility and control, which includes feeling in control of illness and in control of life.

Farkas et $a l^{6}$ argue for values-based practice, then proceed to set out the key values that they believe underpin the concept of recovery that should guide organisational structure and practice. They highlighted four key recovery values.

1 Person orientation: this is evidenced by a service focusing on the individual first and foremost as a person with strengths, talents and interests and not just limitations or exhibiting indicators of disease.

2 Person involvement: the service focuses on people's rights to full partnership in all aspects of their recovery, including partnership in designing, planning, implementing and evaluating the service that supports their recovery.

3 Self-determination/choice: the service focuses on people's rights to make individual decisions or choices in all aspects of their own recovery process including areas such as the desired goals and outcomes, preferred services used to achieve the outcomes, preferred moments to engage or disengage in services.

4 Growth potential: the service focuses on the inherent capacity of any individual to recover, regardless of 
whether, at the moment, he or she is overwhelmed by the disability.

The value of person involvement is further added to by the concept of service users being 'experts by experience' such that the role of the professional becomes more that of a coach and a partner than a traditionally authoritarian role.

\section{What are the values underlying risk assessment?}

Alongside the issues discussed above, there is an expectation of all psychiatric services, in particular forensic services, that they effectively assess and manage the risks that a service user poses to themselves and others. A number of key papers have outlined best practice in these areas, such as the Department of Health's publication Best Practice in Managing Risk ${ }^{7}$ and the Royal College of Psychiatrists' publication Rethinking Risk to Others in Mental Health. ${ }^{8}$ The National Suicide Prevention Strategy for England published in $2002^{9}$ set out plans to meet a target for all psychiatric services to achieve a $20 \%$ reduction in the rate of suicides by 2010 (from a rate of 9.2 deaths per 100000 population to 7.3 deaths per 100000 population). Initiatives to reduce self-harm and suicide rates in high-risk groups continue to be introduced, for example the revised care planning system for prisoners at risk of suicide or selfharm (ACCT, Assessment, Care in Custody, and Teamwork).

These two challenges, both to follow values-based recovery practice and to effectively assess and manage the risks individuals pose to themselves or others, can be seen as being at odds with each other, especially if one compares the values that underlie recovery and those that underlie risk assessment and management.

The first of the four recovery values outlined by Farkas et al was person orientation. ${ }^{6}$ However, clinical risk assessment is often (although not exclusively) focused on third-party risk and is therefore either not, or less, individually oriented. Rogers $^{10}$ has argued that risk assessment does not focus enough on strengths or protective factors when formulating risk, albeit some recent risk assessment tools are attempting to do just that, for example the Short Term Assessment of Risk and Treatability (START). ${ }^{11}$ Values of personal involvement and choice may seem tokenistic when a person is detained in hospital against their will. Self-determination of recovery goals contrasts starkly with the determination of transfer between levels of security or from hospital to the community being based on estimates of risk and fulfilment of Ministry of Justice requirements. The value of growth potential is at odds with certain risk assessment instruments that may rely entirely on static factors, for example the Risk Matrix 2000. ${ }^{12}$ Risk assessment (particularly actuarial) often attempts to place people in 'high-risk' groups based on empirically validated risk factors, which aligns itself with the paradigm of determinism rather than that of growth or choice. The ethical aspect of risk assessment in terms of its predictive accuracy and propensity for false positives for low base-rate behaviours remains a central dilemma in forensic practice.

Another principle of recovery is that of the service user being an expert by experience. However, most risk assessment instruments require specialist training, are often steeped in jargon (for example, 'area under the curve') and involve a professional who has this specialist training estimating a service user's risks. No risk assessment instrument routinely incorporates a service user's own perception of their risk to self or others. Thus clinical risk assessment entrenches the 'professional as expert' role.

\section{Is risk assessment and management anti-recovery?}

At its most basic level, a focus on risk can be seen as antirecovery. Publications arguing for the primacy of the recovery approach, such as Making Recovery a Reality published by the Sainsbury Centre for Mental Health ${ }^{1}$ often state this explicitly, where this publication criticises services for 'a preoccupation with managing risk at the expense of learning'. Farkas et al cite staff training that 'focuses exclusively on issues of relapse, non compliance, dangerousness and risk assessment' violating the values of growth potential and person orientation. ${ }^{6}$ They see staff training in this area as enabling people to deal with risk but not with success. This criticism is counterpointed by the perception by services that there is an increase in political, public and media intolerance of third-party risk caused by mental health patients. Legal requirements for serious untoward incident reporting, 'learning of lessons' after incidents and National Patient Safety Agency guidance ${ }^{13}$ that a safe service is one that is 'preoccupied with failure' all add to this perception.

This dichotomy can perhaps best be exemplified by the statement in the report of the independent inquiry into the care and treatment of John Barrett. ${ }^{14} \mathrm{Mr}$ Barrett was a psychiatric patient from a medium secure unit who went absent without leave and stabbed to death a stranger in a local park. The report stated: 'our overall conclusions in relation to this period of care are that John Barrett's clinical management placed too much importance on his wishes and preferences, with correspondingly less emphasis on the principles of sound risk management'. ${ }^{14}$

It is not unsurprising that psychiatric services may feel they are being asked to achieve the impossible, which is to deliver on two objectives that are at odds with each other. The status quo of this tension in most services lies in the unsatisfactory concept of positive risk-taking. This concept appears to acknowledge the need for risk-taking in the sense that efforts should be made to rehabilitate individuals from a psychiatric hospital back to the community but with all activities having their ceiling first set by clinical risk assessment. These issues were explored by Roberts et $a l^{15}$ who looked at ways of promoting recovery and, in particular, choice, even when patients were detained. Roberts et al reiterated the fact that the common experience of clinicians was that choice and freedom were 'powerfully promoted until an untoward incident occurs, when there can be an intense search for whom to blame and a demand for increasing restriction and control'. ${ }^{15}$ The authors explored ways of promoting choice in areas such as engagement with therapeutic activity, choice of medication, respecting individual needs $v$. group needs and constructive risk-taking. Both professional and service user perspectives of how this could be done were looked at. They concluded 
by suggesting that the way to resolve these tensions was by 'clarifying the story behind difficult interactions, identifying the relevant guiding principles and jointly working to explore from different viewpoints what could be done to promote recovery'. ${ }^{16}$ However, with the paradigm and values underlying recovery and risk seemingly opposite, any recovery-oriented changes to practice run the risk of becoming tokenistic and ill sustained. It is acknowledged that paradigms and values (often unconscious) drive how forensic care is delivered and if they are predominantly riskbased then this will influence organisational structure and behaviour far stronger than any externally imposed drives or initiatives. The question then arises whether this is a conflict that simply needs to be accepted or whether there is a paradigm that can unify concepts of recovery and the assessment and management of risk behaviour?

\section{The human needs model of motivation and behaviour}

I will argue that a unifying paradigm can be found in the human needs model of understanding human behaviour. I will make the case for the human needs paradigm as underlying the recovery approach and the understanding of risk behaviour. Further, I will argue that it is only through a common theoretical framework that risk assessment and management and recovery can be seen as concepts stemming from the same source and not as two opposing forces that must be artificially made to fit together based on broad, but atheoretical, good practice guidelines. In particular, I will argue that the clarification and identification of guiding principles suggested by Roberts et $a l^{16}$ is a recognition that in any negotiation there is a needs conflict and that by identifying the particular needs of both service user and staff for any given situation, ways of meeting these needs for both parties can be explored. This model of needs-based negotiating can be more effective than traditional positional negotiating where the risks associated with a particular request may be looked at and rejected without considering what needs that request was designed to meet and alternative ways of meeting that need.
It also promotes greater openness in dialogue between professionals and service users, allowing the former as well as the latter to acknowledge that both sides have needs that have to be satisfied.

This model stems from the work of Maslow, ${ }^{17}$ from proposed models for offender rehabilitation based on human needs such as the Good Lives Model $^{18}$ and from key authors in the areas of self-help and organisational change such as Steven Covey. ${ }^{19}$ Maslow proposed a hierarchy of needs, often displayed as a pyramid (Fig. 1).

As can be seen, Maslow first proposed that physiological needs have to be met, followed by the needs of safety and security, love and belonging, selfesteem and confidence, ultimately leading to the need for self-actualisation. More recent approaches based on human needs have moved away from a hierarchical model, tending to emphasise a list of common needs that all human beings share and that all need to be met or fulfilled at the same time. All-needs approaches share common theoretical principles as follows:

1 all humans, with or without mental health problems, have the same set of fundamental needs;

2 humans are intrinsically motivated to fulfil these needs;

3 the way human beings fulfil these needs will depend on factors such as belief systems, learned behaviour, skills and opportunities;

4 it is the unsatisfied need that motivates human beings the most;

5 needs can be met both in ways that appear constructive and prosocial or in ways that appear in the short-term destructive;

6 risk behaviours such as violence or self-harm can be seen as behaviours that meet a person's needs, at least in the short term, in the absence of either being able or motivated to use more prosocial ways of meeting these needs.

Models of rehabilitation such as the Good Lives Model purport that by enabling the person to meet their needs in other ways risk behaviour will be reduced.

Different authors use overlapping terminology to describe what they believe to be the fundamental needs of

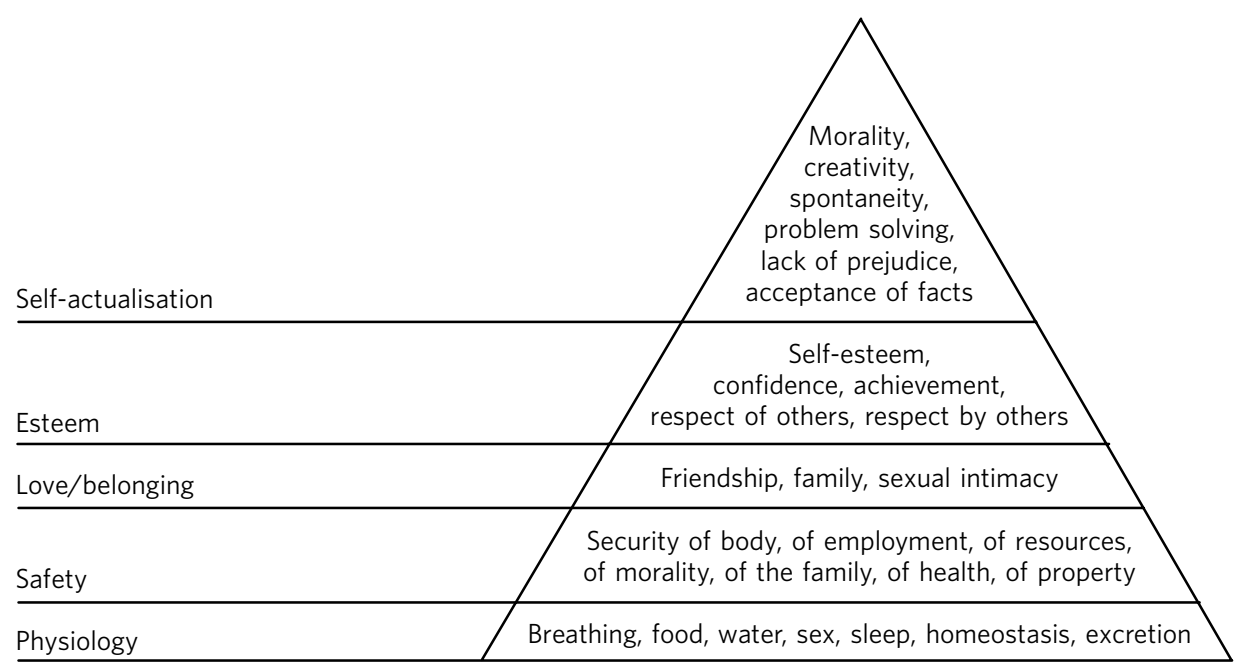

Fig 1 A hierarchy of needs, adapted from Maslow. ${ }^{17}$ 
human beings. For example, the Good Lives Model emphasises nine human needs: healthy living, knowledge, excellence in work and play, excellence in agency (selfmanagement), inner peace, relatedness, spirituality, happiness and creativity. All of these needs are found in Maslow's needs model, albeit ordered differently.

\section{What would a hypothetical, human needs- oriented forensic service look like?}

Here I describe a hypothetical service that would focus on creating an environment and rehabilitation programme that would meet basic human needs. The needs listed below are the ones that are commonly found in prominent human needs models.

\section{The need for security/safety/control over events}

A forensic service would have high staffing levels to promote relational security. Ward routine and rules would be there primarily to provide a containing, consistent and predictable environment. There would be an emphasis on reduction of arousal and the validation of emotional experiences. All aspects of the operational policy of the ward would look for areas that could offer some degree of patient choice and involvement.

\section{The need for variety/creativity/challenge and diversity}

The therapeutic programme must be comprehensive and offer both ward-based and external therapeutic programmes that would include an emphasis on physical health, psychological, vocational and educational programmes. There would be an emphasis on identifying existing strengths and resources and utilising them to aid in recovery.

\section{The need for growth and development}

The rehabilitation would emphasise the role of learning and the application of new skills in a variety of situations.

\section{The need for relatedness, love/connection and belonging}

The service would recognise the central importance of building and maintaining trust in any relationship between the patient and the service and between peers. A ward community ethos would be actively promoted. Friendships within and without the hospital and family contact would be emphasised both in care planning and in budgetary allocation.

\section{The need for importance, to be needed and valued by others and do something of meaning}

The service would have a culture with the values of respect, affirming the worth of everyone's opinion and viewpoint, and dialogue and choice would be emphasised. There would be an explicit focus on the individual outlining their own personal values and aspirations that both influence the content of provided programmes and also help maintain the motivation to engage in such programmes. There would be an active advocacy service and a focus on meeting personalised cultural and spiritual needs.

\section{The need for contribution/to help others}

There would be a focus at all stages on what the individual can do to help contribute, either to the running of the ward, the organisation or the running of the local community through activities such as voluntary work.

If one looks at this hypothetical service, I would argue that this is exactly what a recovery-oriented service would look like and that it is the human needs paradigm that underlies the concept of recovery. Recovery emphasises seeing an individual as a whole person and not just somebody who has a disease or problem. The whole person can be conceptualised as the acknowledgement that people have four dimensions to their nature: mind, body, heart and spirit and that each of these dimensions has their own attendant needs. Thus the human needs approach is essentially a whole person approach. Maslow himself cited that pursuit of higher human needs was a move away from psychopathology. As already alluded to, the human needs paradigm can also offer a powerful understanding of the purpose and function of risk behaviour. For example, it could be argued that a person who exhibits recurrent verbal and physical aggression may be doing so because in the short term these behaviours meet some of their needs such as making them feel significant or important to others, creating variety in what may otherwise be a therapeutically devoid environment and/or meeting the need for being related to others, albeit in a destructive way.

\section{Needs assessment does not replace formulation}

It must be emphasised that there is a danger to superficial understanding of the human needs model. An incorrect interpretation of this model is that recovery (and a reduction in risk) can be simply achieved by more provision, for example more therapeutic programmes, more trips out, more work placements. Taken one step further, the very risk behaviours and other problems one sees can be construed as being caused by social stigma and lack of opportunity for people with mental health problems to meet their needs in more constructive ways. Although more provision of this type is undoubtedly important, a simplistic needs (or human needs) assessment of this type cannot replace a biopsychosocial aetiological formulation.

It has already been stated that different individuals fulfil or meet their needs in different ways, based on a variety of factors including belief systems, knowledge, skills and opportunities. Although human beings are driven to fulfil these needs, according to the model, they do so in an unconscious way. Thus one does not tend to consciously attribute certain thoughts, feelings or actions to meeting one need or the other. Most human behaviour is done habitually. Habits are a pattern of thoughts, feelings or behaviours that, through the process of repetition, have largely become unconscious in the life of the individual. Habit, as argued by Covey, can be seen as lying at the intersection of knowledge, skills and motivation. ${ }^{19}$ For 
someone who habitually self-harms they can be said to have the requisite knowledge of methods of self-harm, the requisite skills to self-harm and to be motivated to do so (because it fulfils one or more needs in the short term). Conversely, an individual with borderline personality disorder may have a human need for relatedness, but lack the requisite knowledge of what a stable healthy relationship is, lack the emotional regulation skills to cope with the intense fear and anxiety that being intimate with another can cause in this patient group, or lack the long-term motivation to develop such skills or knowledge. It is deficits in one or more of these three areas that causes individuals to be more likely to meet their needs in inappropriate or destructive ways, not just because of lack of opportunities or stigma.

\section{What is the purpose of rehabilitation?}

I would argue that rehabilitation (and it is an ongoing debate where the concept of rehabilitation now sits with the advent of the recovery approach) should have three explicit aims that can all lead to an individual being able to meet their needs habitually in non-risky ways: the acquisition of knowledge; the learning and demonstration of new skills; the development and sustaining of motivation.

How would this approach manifest at the clinical level? First, any risk behaviour would be formulated in terms of the needs that it met for an individual usually in the short term. This would serve to reduce the pejorative connotations that repetitive risk behaviours can attract. Second, assessment and management of future risk would not be a mechanical process of listing risk factors or increasing restrictions (and then lessening them after an arbitrary period), but it would involve an analysis of the person's knowledge, skills and motivation to act differently in similar scenarios of risk. One cannot answer this question without an assessment of strengths and resources, internal and external, that the person may be able to draw upon. This would include opportunities in the immediate environment to not act riskily using the same logic as having certain items contraband from the ward.

It is worth looking at how the biological disease model for understanding of psychiatric disorder would fit in with what on the face of it appears a largely psychosocial model. Notwithstanding that some of the needs as described, particularly the physiological needs, would be biologically driven, I would argue that the disease model outlines that there are impairments in the structure and/or biochemical functioning of the brain. The effects of these impairments could be described in terms of their immediate effects, for example frontal lobe damage leading to reduced inhibition of impulses, but could be more thematically organised into impairments that affect either the acquisition or retention of knowledge, the acquisition, retention or new learning of skills, or affecting the ability to maintain and sustain motivation. In this way, the disease model integrates itself well with the human needs approach. Any rehabilitation conceptualised in this way can be largely self-led or serviceled, with both recovery and risk reduction arising as a consequence of an explicit focus on the development of knowledge, skills and motivation.
Recent risk assessments such as the START do include an explicit focus on a patient's strengths. Upcoming revision of the Historical, Clinical, Risk Management-20 (HCR-20) may include assessment of protective factors. ${ }^{20}$ Research looking into the predictive ability of protective factors or strengths to reduce risk and more research into the correlates between recovery-oriented measures, both subjective and objective, and risk-related measures, would be important in providing further validation for this type of approach. Research into START produced a startling finding: where the sum total of strength scores equalled or exceeded the sum total of vulnerability scores, there was no violence for the next 90 days in the patient sample (details available from the author on request). Further research of this type is needed.

\section{Conclusions}

In summary, the human needs model can unify the concept of recovery and risk. Good practice in recovery and clinical risk assessment and management can be achieved by the services' rehabilitation programmes focusing explicitly on the triad of knowledge, skills and motivation, underpinned by an individual biopsychosocial formulation. A final unifying comment on recovery and risk can be offered here. Currently literature mentions the concept of the individual performing meaningful social roles in the community. Any social role inherently carries with it social responsibility that entails an obligation to third parties and to wider society. Said differently, can someone be said to have truly recovered if their risks to themselves or others have not reduced as well?

\section{About the author}

Ashimesh Roychowdhury is a consultant forensic psychiatrist and lead in risk management for St Andrew's Healthcare, Northampton.

\section{References}

1 Shepherd G, Boardman J, Slade M. Making Recovery a Reality. Sainsbury Centre for Mental Health, 2008.

2 Anthony WA. Recovery from mental illness: the guiding vision of the mental health service system in the 1990s. Psychosoc Rehab J 2003; 16: $11-23$

3 Department of Health. From Values to Action: The CNO's Review of Mental Health Nursing. Department of Health, 2006.

4 Royal College of Psychiatrists, Social Care Institute for Excellence, Care Services Improvement Partnership. A Common Purpose: Recovery in Future Mental Health Services. Social Care Institute for Excellence, 2007.

5 Andresen R, Oades L, Caputi. The experience of recovery from schizophrenia: towards an empirically validated stage model. Aust N Z J Psychiatry 2003; 40: 972-80.

6 Farkas M, Gagne C, Anthony W, Chamberlain J. Implementing recovery oriented evidence based programs: identifying the critical dimensions. Community Ment Health J 2005; 41: 141-58.

7 Department of Health. Best Practice in Managing Risk: Principles and Evidence for Best Practice in the Assessment and Management of Risk to Self and Others in Mental Health Services. Department of Health, 2007.

8 Royal College of Psychiatrists. Rethinking Risk to Others in Mental Health Services (College Report CR150). Royal College of Psychiatrists, 2008. 
9 Department of Health. National Suicide Prevention Strategy for England. Department of Health, 2002.

10 Rogers R. The uncritical acceptance of risk assessment in forensic practice. Law Hum Behav 2000; 24: 595-605.

11 Nicholls TL, Brink J, Desmarais SL, Webster CD, Martin M-L. The Short Term Assessment of Risk and Treatability (START): A prospective validation study in a forensic psychiatric sample. Assessment 2009; 13: 313-27.

12 Thornton D, Mann R, Webster S, Blud L, Travers R, Friendship C, et al. Distinguishing and combining risks for sexual and violent recidivism. In Understanding and Managing Sexually Coercive Behaviour (eds R Prentky, E Janus, M Seto). Annals of the Academy of Sciences, 2003.

13 National Patient Safety Agency. Seven Steps to Patient Safety. NPSA, 2004.

$14 \mathrm{NHS}$ London. Report of the Independent Inquiry into the Care and Treatment of John Barrett. NHS London, 2006.
15 Roberts G, Dorkins E, Wooldridge J, Hewis E. Detained - what's my choice? Part 1: Discussion. Adv Psychiatr Treat 2008; 14: 172-80.

16 Roberts G, Dorkins E, Wooldridge J, Hewis E. Detained - what's my choice? Part 2: Conclusions and Recommendations. Adv Psychiatr Treat 2008; 14: 184-6.

17 Maslow AH. Motivation and Personality (3rd edn). Longman, 1970.

18 Ward T, Brown M. The good lives model and conceptual issues in offender rehabilitation. Psychol Crime Law 2004; 10: 243-57.

19 Covey SR. The Seven Habits of Highly Effective People (13th Anniversary Edition). Simon \& Schuster, 2004.

20 Webster CD, Douglas KS, Eaves D, Hart S. HCR-20: Assessing Risk for Violence, Version 2. Mental Health Law and Policy Institute, Simon Fraser University, 1997 